\title{
Childhood lead poisoning: the torturous path from science to policy
}

\author{
David C. Bellinger ${ }^{1}$ and Andrew M. Bellinger ${ }^{2}$
}

${ }^{1}$ Children's Hospital Boston, Harvard Medical School, Harvard School of Public Health, Boston, Massachusetts, USA.

${ }^{2}$ Columbia University College of Physicians and Surgeons, New York, New York, USA.

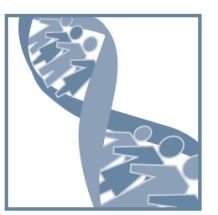

The long history of lead poisoning provides many lessons about the process by which scientific knowledge is translated into public health policy. In the United States, lead was added to paint and to gasoline in enormous quantities long after medical evidence clearly showed that excessive lead exposure caused considerable morbidity in the population. This article discusses some of the factors that contributed to the slow pace of efforts to address this problem, including the ubiquity and magnitude of lead exposure during much of the twentieth century, which produced a distorted notion about the blood lead level that can be considered "normal"; the prevailing model of disease during this period, notably the novelty of the concept of subclinical disease; the fact that childhood lead poisoning affected mostly families that were politically and economically disenfranchised, fostering a "blame the victim" attitude; and that controlling lead exposure would have impeded efforts to achieve other desirable goals, illustrating the role that value trade-offs often play in policy decisions.

The history of lead poisoning over the last century illustrates how the path from sound science to sound environmental policy does not necessarily follow a straight line. Ignorance of the dangers posed by lead was not the primary impediment to addressing the problem. In the second century BCE, the Greek botanist Nikander described the paralysis and colic caused by lead, and 3 centuries later the Greek physician Dioscorides observed that after exposure to lead, "the mind gives way" (1). In 1786, Benjamin Franklin, familiar with lead from his youth as a printer, was surprised that lead poisoning still occurred: "... the Opinion of this mischievous Effort from Lead is at least above Sixty Years old, and you will observe how long a useful Truth may be known and exist before it is generally receiv'd and practis'd on" (2). In 1969, reflecting on the persistence of childhood lead poisoning, pioneering environmentalist Rene Dubos warned that ". . . the problem is so welldefined, so neatly packaged, with both causes and cures known, that if we don't eliminate this social crime, our society deserves all the disasters that have been forecast for it" (3).

When Dubos wrote this, few restrictions had been placed, at least in the United States, on the 2 uses of lead that provided the primary pathways of exposure in the general population: as a constituent of paint for interior residential use and as a gasoline additive. (Among the many other potential sources and pathways of exposure were lead piping and solder, diet, glazed ceramics, storage battery casings, bullets, cosmetics, folk remedies, and leaded glass). On January 1, 1975, the U.S. Environmental Protection Agency issued regulations requiring a gradual phasedown in the amount of lead permitted in gasoline, but for the preceding halfcentury, the addition of up to 4.23 grams of lead per gallon had been allowed (4). The importance of lead emitted from tailpipes as a pathway of human lead exposure was not fully appreciated until the late 1970s, when the Second National Health and Nutrition Examination Survey revealed a precipitous decline in blood lead level in all segments of the population, closely paralleling the

Conflict of interest: The authors have declared that no conflict of interest exists. Citation for this article: J. Clin. Invest. 116:853-857 (2006). doi:10.1172/JCI28232. contemporaneous decline in the amount of lead added to gasoline (5). It was only in 1977 that the U.S. Consumer Product Safety Commission ruled that paint intended for residential use could contain no more than $0.06 \%$ lead by dry weight. Similar actions had been taken about 50 years prior to this in France, Belgium, Austria, Czechoslovakia, Great Britain, Sweden, Cuba, Yugoslavia, Tunisia, Greece, Spain, and Poland (6).

The dramatic decline in population exposures in the final decades of the twentieth century is widely regarded as one of the signal victories in the recent history of public health (Figure 1). In the late 1970s, the median blood lead level of U.S. preschool children was $15 \mu \mathrm{g} / \mathrm{dl}$, and $88 \%$ of children had a level exceeding 10 $\mu \mathrm{g} / \mathrm{dl}(7)$ - the current Centers for Disease Control (CDC) screening guideline (8). Substantial disparities existed as well. The mean blood lead level of poor black children was $23 \mu \mathrm{g} / \mathrm{dl}$, and $18.5 \%$ had a level greater than $30 \mu \mathrm{g} / \mathrm{dl}$. At present, the mean blood lead level of U.S. preschool children is less than $2 \mu \mathrm{g} / \mathrm{dl}$, and fewer than $2 \%$ have a level greater than $10 \mu \mathrm{g} / \mathrm{dl}$. While social and ethnic disparities persist, they are modest compared with those of the 1970s.

As population exposures to lead were decreasing dramatically, the consensus view of "how much lead is too much" was changing as well. As recently as the 1960 s, only levels greater than 60 $\mu \mathrm{g} / \mathrm{dl}$ were considered toxic (9). The level used to define undue lead absorption or elevated blood lead level was revised downward several times in the following decades, based on a steady accretion of epidemiological evidence demonstrating adverse effects of lead on children's neurodevelopment, including reduced IQ scores and learning difficulties, at lower and lower exposures (Figure 2). The level was reduced to $40 \mu \mathrm{g} / \mathrm{dl}$ in 1971, $30 \mu \mathrm{g} / \mathrm{dl}$ in $1975,25 \mu \mathrm{g} / \mathrm{dl}$ in 1985 , and $10 \mu \mathrm{g} / \mathrm{dl}$ in $1991(8,10-12)$. Each time the screening guideline was revised, new studies were initiated to determine whether the new level used to define normal provided children with an adequate margin of safety. Although it is common to see the current screening guideline of $10 \mu \mathrm{g} / \mathrm{dl}$ referred to as a "safety limit" presumed to have special biological significance, the CDC intended it to be interpreted as a risk management tool rather than as a threshold for adverse effect. Research conducted since 


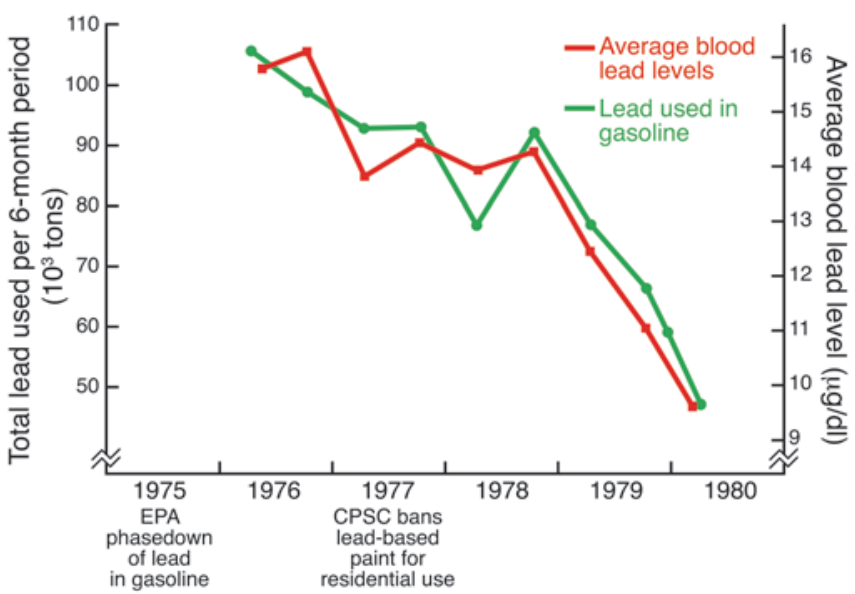

Figure 1

Parallel decreases in average blood lead levels and the amount of lead used in gasoline during 1976-1980 were observed in the National Health and Nutrition Examination Survey II (NHANES II). This followed the 1975 ruling of the Environmental Protection Agency to phasedown the use of lead in gasoline in the United States, which was completed in 1991. Also, in 1977 the U.S. Consumer Product Safety Commission (CPSC) ruled that paint intended for residential use could not contain more than $0.06 \%$ lead by dry weight. Figure modified with permission from Annual Review of Medicine (39).

the last revision of the screening guideline has indeed confirmed the appropriateness of this interpretation, with some results even suggesting that the decline in children's IQ scores per unit increase in blood lead level is greater in the range of $0-10 \mu \mathrm{g} / \mathrm{dl}$ than it is above $10 \mu \mathrm{g} / \mathrm{dl}$ (13). If this controversial observation is correct it indicates that, all recent successes in abating sources and pathways of exposure notwithstanding, much work remains to be done if we are to eliminate lead-associated morbidity in children.

The literature on the mechanisms by which lead achieves its toxicities is very extensive (14). Historically, much of it focused on lead's ability to reduce the heme body pool by inhibiting 2 enzymes in the heme biosynthesis pathway, ferrochelatase and amino levulinic acid dehydratase, producing widespread effects in the erythropoietic, central nervous, renal, endocrine, and hepatic systems (Figure 3). Lead's ability to mimic calcium or to perturb calcium homeostasis, disrupting cell signaling pathways such as the activation of protein kinase C, may be particularly important with respect to its neurotoxicities. Virtually every neurotransmitter system is affected by lead, with the dopaminergic, cholinergic, and glutamatergic systems receiving the most attention. Lead's effects on glutamate release and on $N$-methyl- $D$-aspartate receptor function likely underlie its ability to impair long-term potentiation in the hippocampus.

It is perhaps surprising that it has taken so long to develop accurate estimates of the dose-response relationships for lead toxicity. One reason is that the large changes in population exposure have given all such estimates a historical specificity. Often the blood lead levels of the children selected as "unexposed controls" were, in light of today's knowledge, high enough to cause some toxicity. In one early study, published in 1972, the health outcomes of children in the exposed group (mean blood lead level of $58 \mu \mathrm{g} / \mathrm{dl}$ ) did not differ from those of the control children, but in the latter group, the mean blood lead level was $38 \mu \mathrm{g} / \mathrm{dl}$ and ranged as high as $55 \mu \mathrm{g} / \mathrm{dl}(15)$. The author concluded that the developmental problems observed in the exposed group were due not to lead toxicity, but rather, like the developmental problems observed in the controls, to poor parenting and environmental deprivation. Today many of these "controls" would be candidates for chelation therapy. The ideal controls in a study of lead toxicity would be children without an atom of lead in their bodies. Because such children do not exist, investigators have generally used as controls children with lead burdens that were within limits considered normal at the time the study was conducted. Yet, as noted, this level has posed a moving target, placing constraints on the questions that could even be asked. When almost $90 \%$ of U.S. preschool children had a level above $10 \mu \mathrm{g} / \mathrm{dl}$, it was difficult to design a study to determine whether a blood lead level of $10 \mu \mathrm{g} / \mathrm{dl}$ is associated with demonstrable harm. This could occur only after public health measures instituted in response to the results of previous lead studies had produced a further decline in population exposures, making available sufficient numbers of children who would be suitable controls. Ironically, then, it was in part the restrictions placed on lead's uses that accelerated progress in identifying toxicities at what had been considered normal blood lead levels only a few years before.

Many have concluded that the "lead problem" has largely been solved because the mean blood lead level in children has fallen so low. In 1997, the CDC even changed from recommending that virtually all children undergo blood lead screening to recommending targeted screening of children presumed to be at highest risk (16). Although the progress made in reducing the prevalence of lead poisoning is undeniable, the view that the problem is essentially gone is, in part, an artifact of the units conventionally used to express blood lead level. A level of $2 \mu \mathrm{g} / \mathrm{dl}$ could also be expressed as 2,000 $\mathrm{ng} / \mathrm{dl}$ or as $20,000 \mathrm{ng} / \mathrm{l}$. Although these values are equivalent, they carry different psychological weight. Moreover, low is a relative term. Even current blood lead levels are substantially elevated from an evolutionary perspective, at least 100 -fold higher than estimates of the blood lead levels of our ancestors before they began to disturb the natural distribution of lead in the earth's crust (17-19). Are the blood lead levels of contemporary humans generally below the threshold of toxicity? Let us hope so, but the conclusion that they are is based more on faith than on evidence.

\section{Factors contributing to the slow pace of efforts to eliminate lead poisoning}

Lead poisoning is a prime example of a disease that is anthropogenic in origin (i.e., resulting from human activities) and therefore

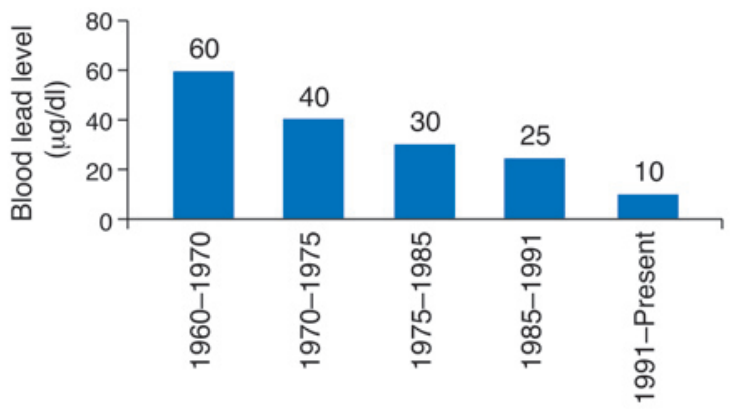

\section{Figure 2}

Change in the definition of elevated blood lead level ( $\mu \mathrm{g} / \mathrm{dl})$ over time. The CDC guideline as to what is considered to be an undue level of lead absorption has continued to decrease over the latter half of the twentieth century. Figure based on data reported in refs. 8, 10-12. 




entirely preventable. As noted previously, it was only after 1970 that major steps were taken in the United States to address the problem. It is instructive to ask why the use of lead remained ubiquitous, and in such immense quantities, throughout most of the twentieth century, even in the face of the accumulating evidence that, by 1969 , Dubos found so compelling. Many factors were likely in play, some of which are discussed in the following paragraphs.

The prevailing model of disease. For much of the twentieth century, public health was governed by a model of disease that was primarily patient oriented rather than population oriented. A child was regarded as lead poisoned or not depending on whether certain clinical signs and symptoms were present. Furthermore, it was thought that a child whose presentation did not include an encephalopathy would recover completely, without significant neurological deficits. In 1943, Byers and Lord's landmark study (20) of a case series of lead-poisoned children showed that both assumptions were wrong. Then, beginning in the 1970s, population-based epidemiological studies revealed the existence of what was labeled subclinical lead poisoning, meaning that exposure caused damage that was not severe enough to meet diagnostic criteria for a neurologic disease but would prevent the child from achieving optimal intellectual functioning (21-24). Because large numbers of children were exposed at these levels, the cumulative morbidity on a population basis could be substantial. What if lead exposure caused a 5-point reduction in the mean IQ in a population, moving it from 100 to 95 ? Because this change is only a little larger than the standard error of measurement of IQ tests, some concluded that lead's impact was within the "noise" of measurement error and thus trivial. If the other characteristics of the IQ distribution remain the same, however, a shift of 5 points in the mean results in a doubling of the number of individuals with scores of 70 or below ( 2 standard deviations below the mean) and

\section{Figure 3}

Lowest observed effect levels $(\mu \mathrm{g} / \mathrm{dl})$ of inorganic lead in children. As lead serves no useful purpose in the body, exposure to it - regardless of route - can lead to toxic effects. Specific physiologic effects of inorganic lead exposure have been associated with major organ systems and functions. Data obtained from ref. 40.

a halving of the number with scores of 130 or above (25). These are not merely statistical abstractions, as empirical observations confirmed them (26). The former decline would require large financial outlays for special education, while the latter would represent a tremendous decline in societal intellectual resources. It has been estimated that the economic benefits of the IQ gain resulting from the substantial reduction in children's blood lead levels between 1976 and 1999 is $\$ 110$ to $\$ 319$ billion for each year's cohort of 2-year-old children (27). In emphasizing population rather than individual effects, lead research appeared to challenge conventional clinical reasoning that focused on individuals rather than the population, but this same perspective is routinely applied in the epidemiologic literature to diseases such as coronary heart disease, hypertension, and obesity (26).

"Blame the victim." The traditional sociodemographic correlates of lead poisoning also contributed to its long neglect. Dubos called this neglect a "social crime" (3). Initially characterized as a "disease of habitation" in Australia in the 1890s (28), childhood lead poisoning has long been known to be most common among poor, minority children living in housing in poor repair. Perhaps as a result of the historical emphasis in clinical medicine on the individual patient and host risk factors rather than on the broader social, political, and economic contexts within which illness occurs, the responsibility for lead poisoning was placed on the victim and his or her family rather than on the dilapidated housing that caused it or on the institutions, policies, and regulations that permitted such lead hazards to exist. Parents, primarily mothers, received much of the blame. They were accused of providing inadequate supervision and nurturance, fostering pathological behaviors such as pica that caused children to ingest lead paint $(29,30)$. As long as the problem was conceptualized in this way, primary prevention of childhood lead poisoning - that is, abatement of major lead hazards before children become poisoned - was not accorded high priority. If poor parenting was the root cause, screening homes for lead hazards would be an inefficient and expensive strategy for eliminating lead poisoning, and indeed for most of the last 50 years the favored approach to prevention was to identify those children who had already been overexposed to lead. In effect, children were treated as sentinels, used to identify the presence of lead hazards in much the same way that miners used canaries to warn of declining oxygen levels.

As long as the ranks of the lead poisoned consisted primarily of the children of politically and economically disenfranchised parents, it was hard to interest politicians in the problem. Little political capital could be accumulated by tackling the problem. In fact, there were disincentives. A politician who took on this issue could risk crossing well-heeled, politically active groups such as the real estate, banking, and lead industries, which generally impeded, rather than supported, primary prevention efforts. It was the social reform movements of the 1960s that began to bring childhood lead poisoning into the public health spotlight. In particular, the civil rights and the environmental movements 




\section{Figure 4}

The Lead-Based Paint Hazard Control Grant Program established by the 1992 Housing and Community Development Act ensures government action to control residential exposure to lead-based paint. Here a worker prepares a surface for wet scraping by saturating it with water during lead-based paint cleanup. The wet method offers the best control of airborne lead levels during removal of hazardous lead-based paint in residential areas. Image credit: Aaron L. Sussell, Centers for Disease Control Public Health Image Library.

long ago, some industries introduced "fetal protection" policies that restricted fertile women of child-bearing age from jobs that involved lead exposure. In 1991, the Supreme Court ruled that such policies violated Title VII of the Civil Rights Act of 1964, which prohibited employment discrimination on the basis of race, religion, national origin, or sex (32). In other words, an employer could not attempt to reduce fetal lead exposure using discriminatory means. As

combined to create concern about environmental justice, based on the observation that poor people were disproportionately affected by environmental hazards such as landfills, municipal incinerators, and housing-related hazards including lead. Political attention to these issues was further stimulated by the steady decline in the CDC's definition of a blood lead level of concern. Each reduction in the screening guideline resulted in a larger percentage of children of families who enjoyed greater social, economic, and political influence suddenly being classified as having an elevated blood lead level. And the number of such children grew as more and more affluent families moved back into inner-city neighborhoods to rehabilitate older homes with deteriorated lead-based paint. With access to the resources needed to effect policy change, such families were often galvanized into action at the grass-roots level by their experiences.

\section{Clash of competing goals}

Finally, the decision about whether and how to address an environmental exposure that carries health risks does not occur in a vacuum but in a complex, value-laden context in which other needs compete for attention and resources. In the 1920s, scientists at General Motors discovered that the addition of tetraethyl lead to gasoline boosted its octane rating, enabling the development of high-compression engines, an important step in meeting the transportation needs of a rapidly expanding economy. One executive of the Ethyl Corporation, the General Motors subsidiary formed to market the product, said that "our continued development of motor fuels is essential in our civilization" and called lead "a gift of God" (31). These arguments won the day over those of the less sanguine but prescient public health advocates, one of whom predicted that "conditions would grow worse so gradually and the development of lead poisoning will come so insidiously... that leaded gasoline will have been old ... before the public and the government awaken to the situation" (31).

On occasion, the pursuit of one laudable social justice goal necessarily impedes the achievement of another laudable goal. Because the hazards of prenatal exposure to lead were recognized a result, fetuses continued to be exposed to lead levels that were known to cause reproductive toxicity.

\section{Conclusion}

The long history of lead offers a variety of lessons relevant to the current controversies regarding childhood exposure to other environmental chemicals such as polychlorinated biphenyls, methyl mercury, pesticides, arsenic, and manganese. First, the average level of exposure to a chemical in a population is not necessarily the same as the physiologically normal level. Consequently, identifying the subclinical effects of a prevalent toxicant can be difficult, requiring large, lengthy, and costly epidemiological studies, and often successive waves of studies as the distribution of exposures within the population changes over time. Because the studies are necessarily observational rather than experimental, the many potential sources of bias can make the process of drawing inferences about causality contentious. In the case of lead, the deep similarities between the findings of the epidemiological studies and those of the rich experimental literature using animal models proved critical in establishing the plausibility of the inference that the human findings resulted from a causal role for lead rather than from a bias or other methodological artifact.

Second, education about a hazard and steps that a family can take to reduce risk are important public health measures but are by themselves inadequate as a means of achieving primary prevention (33). A more active institutional commitment to address the problem is required. Historically, the major public health response to childhood lead poisoning has been secondary prevention, namely screening to identify children that have already suffered elevated exposure. Unfortunately, even this effort has been inadequate. A recent Government Accountability Office report revealed that although lead screening is required as part of the Early and Periodic Screening, Diagnosis and Treatment Program for children covered by Medicaid (34), it is carried out on fewer than $20 \%$ of such children (35). Moreover, one must question whether secondary prevention is an acceptable alternative to primary prevention when the neurologic injuries caused by excess lead exposure are irreversible 
(36) and medical treatments such as chelation are ineffective (37). Some progress toward primary prevention is being made. The LeadBased Paint Hazard Control Grant Program was established by Title $\mathrm{X}$ of the Housing and Community Development Act of 1992. This program, administered by the U.S. Department of Housing and Urban Development, is designed to fund state and local government efforts to reduce residential lead-based paint hazards (Figure 4). A recent nationally representative survey revealed that between 1990 and 1998-2000, the number of U.S. housing units with leadbased paint declined from 64 million to 38 million (38).

Third, throughout the twentieth century, the lead industry showed little inclination to regulate itself through voluntary constraints (4), which made it necessary for constraints to be imposed upon them through statutory regulations. Because of the consequences and cost of such regulations, including their potential for stimulating litigation, the evidentiary standards required by policy makers are usually very high. The tension between the economic costs of action and the health costs of inaction is a central issue when new regulations are considered.

Fourth, risk is not distributed equally. It is often the least advantaged in our society that suffer the most from environmental chemical exposures such as lead. Whether we elect to protect those who are the most vulnerable to lead, and in many respects the least able to protect themselves, reflects, for better or for worse, our societal values.

Address correspondence to: David C. Bellinger, Farley Basement Box 127, Children's Hospital Boston, 300 Longwood Avenue, Boston, Massachusetts 02115, USA. Phone: (617) 355-6565; Fax: (617) 730-0618; E-mail: david.bellinger@childrens.harvard.edu.
1. Major, R.H. 1931. Some landmarks in the history of lead poisoning. Ann. Med. 3:218-227.

2. Tackett, S.L. 1981. The Franklin letter on lead poisoning. J. Chem. Educ. 53:274.

3. Oberle, M. 1969. Lead poisoning: a preventable childhood disease of the slums. Science. 165:991-992.

4. Lewis, J. 1985. Lead poisoning: a historical perspective. US Environmental Protection Agency. http:// www.epa.gov/history/topics/perspect/lead.htm.

5. Annest, J.L., et al. 1983. Chronological trend in blood lead levels between 1976 and 1980. N. Engl. J. Med. 308:1373-1377.

6. Markowitz, G., and Rosner, D. 2000. "Cater to the children": the role of the lead industry in a public health tragedy, 1900-1955. Am. J. Public Health. 90:36-46.

7. Mahaffey, K.R., Annest, J.L., Roberts, J., and Murphy, R.S. 1983. National estimates of blood lead levels: United States, 1976-1980. Association with selected demographic and socioeconomic factors. N. Engl. J. Med. 307:573-579.

8. Centers for Disease Control. 1991. Preventing lead poisoning in young children. A statement by the Centers for Disease Control-October 1991. U.S. Department of Health and Human Services. Atlanta, Georgia, USA. 108 pp.

9. Chisolm, J.J., and Harrison, H.E. 1956. The exposure of children to lead. Pediatrics. 18:934-955.

10. [Anonymous]. 1971. Medical aspects of childhood lead poisoning. Pediatrics. 48:464-468.

11. Centers for Disease Control. 1975. Increased lead absorption and lead poisoning in young children. U.S. Department of Health, Education, and Welfare. Atlanta, Georgia, USA. 593-611.

12. Centers for Disease Control. 1985. Preventing lead poisoning in young children. A statement by the Centers for Disease Control-January 1985. U.S. Department of Health and Human Services. Atlanta, Georgia, USA. 107 pp.

13. Lanphear, B.P., et al. 2005. Low-level environmental lead exposure and children's intellectual function: an international pooled analysis. Environ. Health Perspect. 113:894-899.

14. Agency for Toxic Substances and Disease Registry (ATSDR). 2005. Toxicological profile for lead. (Draft for public comment). U.S. Department of Health and Human Services. http://www.atsdr.cdc. gov/toxprofiles/tp13.html\#bookmark16.

15. Kotok, D. 1972. Development of children with elevated blood lead levels: a controlled study. J. Pediatr. 80:57-61.

16. Centers for Disease Control. 1997. Screening young children for lead poisoning: guidance for state and local public health officials. U.S. Department of Health and Human Services. Atlanta, Georgia, USA. 122 pp.

17. Patterson, C.C. 1965. Contaminated and natural environments of man. Arch. Environ. Health. 11:344-360.

18. Flegal, A.R., and Smith, D.R. 1992. Lead levels in preindustrial humans. N. Engl. J. Med. 326:1293-1294.

19. Mushak, P. 1993. New directions in the toxicokinetics of human lead exposure. Neurotoxicology. 14:29-42.

20. Byers, R., and Lord, E. 1943. Late effects of lead poisoning on mental development. Am. J. Dis. Child. 66:471-494.

21. Needleman, H.L., et al. 1979. Deficits in psychologic and classroom performance of children with elevated dentine lead levels. N. Engl. J. Med. 300:689-695.

22. Yule, W., Lansdown, R., Miller, I.B., and Urbanowicz, M.A. 1981. The relationship between blood lead concentrations, intelligence, and attainment in a school population: a pilot study. Dev. Med. Child Neurol. 23:567-576.

23. Winneke, G., et al. 1983. Neuropsychological studies in children with elevated tooth-lead concentrations. II. Extended studies. Int. Arch. Occup. Environ. Health. 51:231-252.

24. Fulton, M., et al. 1987. Influence of blood lead on the ability and attainment of children in Edinburgh. Lancet. 1:1221-1226.

25. Weiss, B. 2006. Methylmercury: a model neurotoxicant and risk assessment dilemma. In Human developmental neurotoxicology. D.C. Bellinger, editor. Taylor \& Francis. New York, New York, USA. In press.

26. Bellinger, D.C. 2004. What is an adverse effect? A possible resolution of clinical and epidemiological perspectives on neurobehavioral toxicity. Environ. Res. 95:394-405.

27. Grosse, S.D., Matte, T.D., Schwartz, J., and Jackson, R.J. 2002. Economic gains resulting from the reduction in children's exposure to lead in the United
States. Environ. Health Perspect. 110:563-569.

28. Gibson, J.L. 2005. A plea for painted railings and painted walls of rooms as the source of lead poisoning amongst Queensland children. Public Health Rep. 120:301-304.

29. Hunt, T., Hepner, R., and Seaton, K. 1982. Childhood lead poisoning and inadequate child care. Am. J. Dis. Child. 136:538-542.

30. Stark, A., Quah, R., Meigs, W., and DeLouise, E. 1982. Relationship of sociodemographic factors to blood lead concentrations in New Haven children. J. Epidemiol. Community Health. 36:133-139.

31. Rosner, D., and Markowitz, G. 1985. A 'gift of God'?: the public health controversy over leaded gasoline during the 1920s. Am. J. Public Health. 75:344-352.

32. Annas, G. 1991. Fetal protection and employment discrimination: the Johnson Controls case. N. Engl. J. Med. 325:740-743.

33. Centers for Disease Control. 2002. Managing elevated blood lead levels among young children: recommendations from the Advisory Committee on Childhood Lead Poisoning Prevention. U.S. Department of Health and Human Services. Atlanta, Georgia, USA. 128 pp.

34. US Health Care Financing Administration. 1998. Part 5: early and periodic screening, diagnosis, and treatment (EPSDT). In State Medicaid manual. US Health Care Financing Administration. Baltimore, Maryland, USA. HCFA Publication no. 45-5. Section $\$ 5123.2$ /Transmittal no.12.

35. Centers for Disease Control. 2000. Recommendations for blood lead screening of young children enrolled in Medicaid: targeting a group at risk. Morb. Mortal. Wkly. Rep. 49:1-13.

36. Bellinger, D.C. 2004. Lead. Pediatrics. 113:1016-1022.

37. Rogan, W.J., et al. 2001. The effect of chelation therapy with succimer on neuropsychological development in children exposed to lead. N. Engl. J. Med. 344:1421-1426.

38. Jacobs, D.E., et al. 2002. The prevalence of leadbased paint hazards in U.S. housing. Environ. Health Perspect. 110:599-606.

39. Needleman, H. 2004. Lead poisoning. Ann. Rev. Med. 55:209-222.

40. Agency for Toxic Substances \& Disease Registry. Lead toxicity physiologic effects. http://www.atsdr. cdc.gov/HEC/CSEM/lead/physiologic_effects.html. 